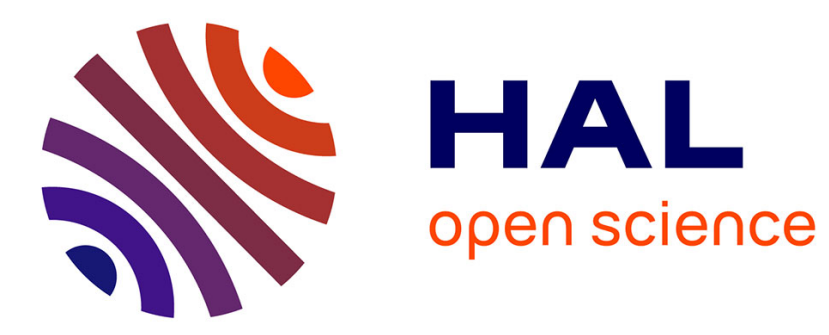

\title{
From networks of cities to systems of cities
}

Denise Pumain

\section{To cite this version:}

Denise Pumain. From networks of cities to systems of cities. Rozenblat C., Neal Z. Handbook of Cities and Networks., Edward Elgar Publisher, pp.16-40, 2021, Handbook of Cities and Networks, 978-178811-470-7. halshs-03326154

\section{HAL Id: halshs-03326154 \\ https://shs.hal.science/halshs-03326154}

Submitted on 25 Aug 2021

HAL is a multi-disciplinary open access archive for the deposit and dissemination of scientific research documents, whether they are published or not. The documents may come from teaching and research institutions in France or abroad, or from public or private research centers.
L'archive ouverte pluridisciplinaire HAL, est destinée au dépôt et à la diffusion de documents scientifiques de niveau recherche, publiés ou non, émanant des établissements d'enseignement et de recherche français ou étrangers, des laboratoires publics ou privés. 
Pumain D. 2021, From network of cities to systems of cities, in C. Rozenblat and Z. Neal (eds) Handbook of Cities and Networks. Cheltenham, Edward Elgar Publisher, pp. 16-40.

\title{
From networks of cities to systems of cities
}

Denise Pumain

pumain@parisgeo.cnrs.fr

\begin{abstract}
This chapter elaborates on a shift in urban theories from a static and structural view of "networks of cities" in a territory toward a systemic conceptualization and dynamic analysis of interdependencies and co-evolution in complex systems. The major concepts and methodological issues that were used in the process of theory building are reviewed during three major stages in the history of the science of cities, including examples taken mainly from the literature in Europe and United States. In a first step, the role of communication networks in the historical evolution of cities is intuitively described and the first measurements of cities spacing, size and functions lead to the construction of formal theories of networks of cities according to static models as central place theory and rank-size distribution. In a second step the dynamics of city networks is inferred from statistical analyses and cross sectional comparisons of the attributes of large numbers of cities at different points in time leading to constructing an evolutionary theory of systems of cities and including inter-urban communication and spatial diffusion of innovation. In a third step the growing availability of urban data, especially about urban interactions, and the increased power of computing algorithms enable to fully explain this evolutionary theory of systems of cities by including features of complex systems as bifurcations, fractals or scaling laws as well as theories of social sciences about networks, innovation and social change. This comprehensive theory is both exemplified on a huge variety of empirical data and tested through dedicated simulation models.
\end{abstract}

Keywords: System of cities; urban theory; urban modeling; inter-urban networks; evolutionary theory; epistemology; history of geography

\section{Introduction}

Philosophy then social sciences took interest in defining what a city is and finding ways for improving its political organization, shaping its esthetics or developing its performance. Many theories flourished that provide a vision about what "a" city is or how it should be. For example, economists constructed, since the first suggestions by Marshall (1890) a theory of "the" city as a means of offering agglomeration economies that provides a subset of diverse "externalities" favorable to enhance the functioning and development of firms (Fujita et al. 1999). Among all the social sciences, geographers were the first, followed by historians and archaeologists, to engage in searching for a theory that is not that of "the" city but which readily admits that cities form in networks connecting cities of differentiated size and function (Peris et al. 2018).

Building a theory is a complex and long process. Ideally starting with observation, measurement, following a formalization in logical, mathematical or computing models, then 
validation through many empirical testing on international comparisons, it also interferes with available data, technologies, current scientific paradigms and ideological backcloth of the time during the course of history. Many controversies and personal or political rivalries take their place in what is by no means a linear and regularly constructive process. We shall provide here a very simplified historical view by reducing the emergence of urban theories to three main steps : first, from the observation of their relationships with territories and trade networks; second, how they integrated observation of socio-economic changes within concepts of systems dynamics and co-evolution; and third, how they may take further inspiration from the recent availability of not yet fully explored data about real time interaction networks at all geographical scales.

\section{Territorial rather than reticular principle}

The first axiom of geographical urban theories is that cities are never isolated but organized in systems of interconnected cities, over territories of more or less large dimension (Berry, 1964; Rozenblat et al. 2018; Pumain, 2020). Based on observations of cities over the very long term, whatever the forms of political and economic organization of societies, it seems established that cities never appear in isolation, but always (or, let us say, with a very high statistical frequency) as sets of cities connected by different types of relations and exchanges (Fletcher, 1986; Renfrew \& Poston, 1979; Liu 1996). Trade and/or violent predation have allowed cities to accumulate wealth in a more efficient way than villages had been able to do since the "Neolithic revolution" (storage and then the invention of agriculture), which had already multiplied population densities by a factor of one hundred compared to hunter-gatherer populations (Markus \& Sabloff, 2008).

Cities differ from villages. Even if their definition may vary according to cultural areas and countries of the world, they are generally characterized by the importance of the nonagricultural activities that developed there. Cities have freed themselves from the constraints of resource limitations and uncertainties in their immediate environment (their "site") by establishing connections with other sites, in order to find complementary resources and reduce the effects of local hazards (Reymond, 1971). In this way, they build up a "geographical situation", defined in terms of accessibility to other sites and other types of resources, which enables them to resist the consequences of natural hazards (earthquakes, climatic accidents, epidemics) or conflicts (wars and predations) occurring on their site and in their neighborhood. Above all, thanks to higher densities, the interactions generated by proximity within and between cities increase the probability of innovations appearing through the exchange and hybridization of local inventions, and give cities powers for capturing and accumulating resource far greater than those villages provide ${ }^{1}$. This may explain why the urbanization process has profoundly transformed the settlement of human societies on the earth surface with the progress of technologies and complexity of societies since the emergence of the first cities some 10,000 years ago. From multiplying the probabilities of fruitful interactions and widening their range, the spatial organization of cities including multilevel networks is a partly endogenous engine for ensuring the urban development (Smith, 2014).

\footnotetext{
${ }^{1}$ For a more complete and concrete definition, with the example of Roman empire, see the chapter by J.W. Hanson in this book
} 
In the spatial patterns of emergence of these sets of cities, two organizing principles are classically identified, each corresponding to one of the two main definitions of promoting spatial interactions through geographical proximity and accessibility. We call the territorial principle the one based on neighborhood proximity, measured in kilometers. The reticular principle defines proximity by the capacity to access communications in a network and is measured by indices of connectedness. In reality, whatever the historical era or the geographical area, these two principles are always closely associated in all practices related to proximity. Close neighborhoods develop with networks of roads that allow for pathways and routes between resources and habitats, and long distance networks are only effective if they link territories between which there is an exchange of resources, population and information. Depending on the place and time in history, it is objectively true that certain types of relationships may have prevailed in the formation of cities and the systems they build (Pirenne, 1925; Vance 1970; Bird 1973). But it is also a matter of deliberate choice if some urban theories do insist on the role of networks or leave it implicit (Pumain, 1992; Camagni 1993; Pumain, Robic, 1996).

\subsection{Cities and the territory: the implicit network}

The cities participated of the spatial organization of territories, i.e. part of the Earth surface that were dominated by a sub-group of human population that used its resources and designed its specific linkages with the organization of the society. Within the ancient representations in terms of military strategy, political domination, organization of agricultural markets and distribution of goods, the cities are part of a territorial coverage. The city is considered here in a process of paving the geographical space. It controls a region, disposes of it or serves it: it dominates a territory.

In ancient Europe and Asia, cities were defensive places protected by walls that were together with other signs of urbanity (such as wealth, beauty and hygiene), one of the signs of the grandeur of the place. As early as the 17th century in France, the defensive system changed scale and was transferred from the locality to the kingdom (Pumain \& Robic, 1996). Vauban built a series of fortifications along the borders, classified in three orders: the fortified squares surround the "pré carré", a continuous territory whose limits were defined. The theoretical representation of a system of military squares organized to protect the whole territory was formulated later in the first half of the 18th century, including a spatial model of the spacing between places, the hierarchy of sizes, and their depth arrangement. The speed at which troops moved, the time it took to transport food and ammunition, and the duration of resistance to siege, all of which are themselves inducers of seat size, governed the framework of this system. The organization of the military space tends to control the organization of the civil space. For a number of theorists, the hierarchy of war zones is in line with that of the kingdom's cities. The communication routes, essential to the functioning of the strategic system, are subject to particular control by the Engineers. Under the Restoration, strategic thinking became even more precise by underlining the problems of interdependence and hierarchy between the points of the territory. It is moreover in military art that the notion of "network" (the "plan of the permanent network of fortifications", 1821) appears at the same time.

Like the art of war, reflection on political or administrative domination has generated a theoretical representation of the city as the center of a paving of space. The capital is, par excellence, the city that ensures territorial control: center of concentration of power, place of 
demonstration, node of information systems that cover the country from the center to the periphery. Synonymous with asymmetrical relations, it is the metropolis, the head, whose impulses are transmitted in small parts by a series of "capitals". Such a view is well illustrated by Marco Polo's description of the Empire of the Great Khan according to the main cities and political articulations. He accompanied his description of the cities with a qualifier that roughly corresponds to their rank in the administrative hierarchy of China.

No political theory of cities was formulated during the French Revolution: the Constituents' debates on departmentalization focused primarily on the size of the constituencies and paid little attention to cities, in an anti-urban attitude that prolonged that of the 18th century (OzoufMarignier, 1989). The representations of the city brought into play are of two kinds: the cultural, traditional representation, which emphasizes urbanity, the quality of the elites gathered as much as the beauty and healthiness of the place. A more novel functionalist representation emerges at that time which, by emphasizing the role and activities of the city, takes into account the city's relationship with its environment, in terms of jurisdiction and centrality. This structure of vernacular representations and representations of the Constituents is consistent with the interpretations given by B. Lepetit (1988) of the spatial structures identifiable in the $18^{\text {th }}$ century, cities are for the most part locally anchored; they constitute a whole without systematic dependencies and with a low degree of hierarchy ${ }^{2}$. It is with the Saint-Simonians and the construction of railways at the beginning of $19^{\text {th }}$ century that this perspective changes.

\subsection{Urban hierarchy such as described with central place theory}

Reflection on the city as a market serving a certain catchment area or rural "fallout", which in turn supplies it and supports its growth, is very old and prevailed much before achieving the overall formalization of the service of a territory by cities. The latter is rooted in theories such as those of the economist Cantillon or von Thünen's theory of the isolated state (1826). Von Thünen situates the organizing role of the city by showing the dependence of the agricultural territory on the accessibility to the market-center, responsible for the concentric structure of the land use around it, but his model does not consider the urban repercussions nor the relationships established between neighboring sub-systems.

During the $20^{\text {th }}$ century, the emergence of the notion of services (and "tertiary" activities according to Colin Clark's classification) encouraged the flowering of research on areas of urban influence. Many empirical studies took place during the inter-war period, whether in an academic framework in Europe (Great Britain, France and Germany in particular) or in the framework of applied research (United States): the bibliography accompanying the theory of central places proposed by Robert Dickinson (1934) testifies to this abundance of research on the service areas of American cities.

In a similar way, the major systematic studies of regional "urban networks" carried out by European geographers, even until the 1960s still give priority to the study of city-rural relationships rather than city-to-city relationships. The idea of a total coverage of the territory by cities underlies the descriptions that geographers made in the middle of the 20th century, despite their use in French of the expression "urban network". At that time, the "network" of cities was almost never studied as a set of nodes and lines. In a perspective inspired by Marxism,

\footnotetext{
${ }^{2}$ Bernard Lepetit entitled a chapter about the equipment of paved roads all over France in 18th century

"l'impensable réseau" - the unthinkable network.
} 
which characterized the city as a predator, a landowner taking benefit from the rent, the question of rural levies underpins empirical investigation, through the study of land ownership. Thus, in many works, it is a representation of the city rooted in a rural space that guides the conception of the coverage of the territory by cities. However, it is less the question of land rent than that of commercial exchange and consumption of services that was to give rise to the theorization of sets of cities as hierarchies of central places. Even if the Saint-Simonian Jean Reynaud (1841), "discovered" by Robic (1982), invented the theory, it is the geographer Walter Christaller (1933) who one century later stands out as a symbol.

Christaller's central places theory aims at explaining the number, size and spacing of cities (Christaller, 1933). Its major postulate is that cities organize the territory to which they provide services in a more or less regular spatial and hierarchical pattern of centers characterized by different levels of urban functions. The example of the medical service supports this demonstration. Centrality is defined by the exercise, in a city, of an activity intended for an external clientele, located in the "complementary region", contiguous to the city. The spatial range of the service, based on the transportation cost that consumers agree to add to the cost of the good requested, and the threshold of appearance, the volume of clientele necessary for the survival of the service supply, regulate the spacing of the centers. Low-cost or frequently used goods have smaller ranges than more expensive or less commonplace goods. Goods and services of comparable scope are grouped in the same centers, and centers at a given level have all the functions of lower-level centers, plus a few. From circular, the service area becomes hexagonal to account for the vicinity of other centers at the same level without overlap. The number of centers and their arrangement may differ slightly according to three different criteria. The market principle provides the best possible accessibility to the centers for customers. The transport principle leads to a smaller number of centers arranged in a way that limit the length of communication routes needed to link the centers. The administrative principle characterizes the inclusion of an entire lower level administrative district in the upper level administrative district, instead of sharing the clientele between competing centers as in the case of the previous two principles. On the maps drawn up by Christaller for southern Germany or for the whole of Europe, as on the diagrams of his models, the boundary between urban catchment areas is always strongly drawn. The "complementary regions" (or market areas) are disjointed and constitute a complete paving of the territory. In his first applications of the gravity model, Reilly (1929) sought to calculate the location of this boundary. It was only much later that their probabilistic (Huff, 1963) or blurred (Ponsard, 1977) character, or even the possible discontinuities of the areas of influence, were insisted upon.

The urban hierarchy such as conceived in central place theory derives from the functional levels rather than from the spatial organization of the nodes. The hierarchy of cities is thus a different notion from the concept of hierarchy used to describe the organization of institutions, linked to the exercise of a specific power or attributions. The urban hierarchy is mainly a differentiation of functional levels. This notion is based on the recurrent observation in empirical studies of the presence of certain facilities, shops or services in certain cities, and on the fact that these centers have several levels, graded by the frequency of appearance, the rarity of use and the spatial scope of these functions, by the size of their zones of influence, and by the diversity of the functions gathered. Generally, but not always, the rarity and diversity of functions are greater the larger the size of a city. This essential property of urban networks has been recognized as fundamental since its first mention in the literature. Jean Reynaud (1841) based his description of what he named the "system of cities" on the existence of several levels of 
services. While the inhabitants of villages group together under the impulse of "sociability", craftsmen concentrate in one of these villages, "not only because of the pleasure they have in being together", but also "because of the continual need they have for each other" (what we would today name agglomeration economies). Placed at the center of a hexagon in which it serves several villages, this village of artisans is itself, along with others, part of a higher-level center for the use of less frequently used services. The author believes that three to four levels of centers between the simple village and the capital of a large country can be detected.

The two major principles of central place theory - central supply of services, grouping of services at the same level in the same centers - are at the origin of a nested hierarchy of levels of functions, the design of which has greatly guided the theorization and analysis of the regional sets of cities that French-speaking geographers will name "urban networks" in the 1960s. In the formulations of Christaller (1933), in the experimentations carried out by Berry (1967), after Lösch (1940) in the Iowa plains, in the mathematical models proposed by Beckman and McPherson (1970), in the many works on regional urban networks and in tests of the theory quoted by Berry and Pred (1965), or Parr (1985), urban hierarchy is almost never deduced from the analysis of city-to-city relations, from the observation of flows or exchanges between cities, or even and especially from direct measures of dependence, domination or "command" (despite the sporadic use of this term in the literature). Indeed, the ordered levels of the urban hierarchy are deduced from the degree of rarity and spatial range of their activities. The facts of polarization, i.e. the organization of flows centered on cities, are most often used only to measure the extent of areas of influence and to help identify levels among centers. At most, a few analyses mention the concentration of decision-making power in certain higher levels of the hierarchy - for example, with regard to banking power. These allusions are obviously more frequent in connection with administrative organization and comparisons between urban networks that are more or less centralized or "dominated" by a particular metropolis or capital city.

However, the nesting of the levels, as shown by observations, is not as perfect as in theory. There are "overlaps" of competence, equipment is lacking in some centers where it should normally be, and on the contrary is present in centers that are "too small". B. Berry, R. Preston, G. Golledge and many others have discussed this "vagueness" in the hierarchy of central locations. Seeing the urban hierarchy as a set of centers emanating from a territory that they frame and serve cannot fit with all observable urban networks. For example, specialized cities such as major seaports or mining and steelmaking centers were sometimes considered in the literature of that time as "off the grid"! The specialization of a limited number of cities in activities that are not trivial services to the population is, however, a characteristic property of urban networks, admittedly of secondary importance but just as universal as their hierarchical organization (Paulus and Vacchiani-Marcuzzo, 2015). Present in Lösch's models, postulated by the economic base theory (Hoyt 1961) as well as by that of growth poles (Pumain \& Torre, 2020), specialization has nevertheless remained until recently poorly integrated into the territorial theory of urban networks, perhaps due to the lack of an explicit formulation of the nature and form of the relations that are established between cities. It is only recently that the improved availability of data on a variety of interurban flows enabled to map the multilevel spatial organization of French cities in different types of sub-systems according to the range an nature of their interactions (Berroir et al. 2017). We shall see in section 2.3 how taking into account the dynamics of urban systems and modeling the genesis of their structure through their socio-economic interactions necessitate a description of the inter-urban networks that do not 
belong to the common customer services observed in central place theory but are generated by more "specialized" urban activities.

In short, these formalizations of the "urban network" are partial in the theoretical field they address: the service of the population living in the territory, but also in their formal orientation, which neglects the interrelationships between the nodes of the network. The ambiguity of using the expression "urban network" in the work inspired by central place theory is apparent. Although Christaller calls one of his models a "transport model", its purpose is only to see, which effects has an economy in the construction of traffic routes on the spatial pattern of cities. The model does not specify the possible hierarchy of roads by traffic, nor the intensity of the relationships. It is also revealing that the concept of centrality, which could connote a position in a network, was explicitly defined by Christaller as the ability of a city to offer goods and services to an external clientele located in the "complementary region" adjacent to the city. The criticisms addressed to central place theory today largely concern its reference to the interpretative form of "territorial coverage", which leads to explain the hierarchical and spatial form of an urban network by its function of controlling and serving a territory. As the majority of the population now lives in cities, some people believe that it is an aberration to conceive a theory where the entire urban organization depend on the services provided to rural populations in "complementary regions". Other critics question an oversimplified representation in this theory of the behavior of actors, close to that of "homo economicus" minimizing transport costs for each product. Several authors have endeavored to study the consequences of more complex behaviors, such as that of "multiple-purpose purchasing trips" on the spatial forms of urban networks, and more generally to make the foundations of the theory more explicit at the individual level, i.e. those relating to the behavior of households and businesses (Beguin, 1988; Fujita, 1989). Moreover, the presence of specialized functions, whose logic of location is ahierarchical, may explain why, instead of distinct levels as expected from central place theory, there is always an almost continuous statistical distribution of city sizes (Beguin \& Thisse, 1979). Finally, central place theory is criticized for its static character: the hierarchy of cities and the models of spatial organization correspond to a situation of equilibrium in which a territory is shared between competing centers.

However, in the previous century, both Jean Reynaud and the geographer Kohl (1841), whom Christaller quotes, had strongly emphasized the interdependence between traffic routes and cities as trade nodes. The conception of the city as a node in a communications network is indeed another very old representation of cities.

\subsection{Cities as stops along long-distance routes}

The reticular principle is advocated for explaining the historical emergence of subsets of cities where interdependencies have been built up, less in connection with the resources of a local or regional territory, than on the enormous profits derived from the exchange of rare products over very long distances. These exchanges have spatial ranges that are out of all proportion to the smaller scopes of the most frequent spatial interactions permitted by the state of transport technology at a given time (Renfrew 1975). Cities thus also formed in networks of stops along routes, based on exchanges of expensive and coveted products, such as the many cities along the "Silk Roads". They form urban networks staggered along traffic routes, the location of which often corresponds to major accidents of the relief that have from the outset facilitated passage or navigation (MacKinder 1890; Pirenne 1925). There are numerous examples, as the 
Phoenician trading posts (1200 BC) including the towns of Tyra, Cyprus, Crete, Sicily, Malta, Cadiz in Spain or Carthage, or the Venetian trading posts of the 13th-15th centuries also spread around the Mediterranean. The Hanseatic towns of the 12th-17th centuries along the Baltic Sea were an example of multilateral network creation through trading contracts, whereas the cities of "triangular" trade associated with the European colonial empires from the 16th to the 19th century formed a network between Africa, North American and Europe. More recently, the chain of ports along the maritime container route in Asia (Ducruet, 2008; Ducruet et al. 2018) or even to the nodes of the world financial markets that complete the daily transaction time in only three major "stops" in very powerful economic centers (New York, Tokyo, London) are examples of how functional networks can shape urban patterns. In these networks of cities, the trade links build interdependencies that ensure the development of cities for as long as the exclusivity and profitability of these specialized exchanges lasts.

The effect of the reticular principle also appears in what has been characterized as the constitutive "duality" of urban networks in developing countries having undergone colonization (Taafe et al., 1963). A former more or less regular network of "central places" founded by local markets and polities according to the territorial principle has been superimposed by a network of disproportionately large urban centers, usually seaports, whose development is associated with an economy of a much wider scale (for example, three of India's four largest metropolises are of this type (Swerts et al., 2018). The exchanges associated with these exceptional urban developments differ from those of the former networks of continental or maritime stops along roads by the strong qualitative and quantitative asymmetries of center-periphery relationships. These cases result in a "macrocephaly" characteristic of many former colonized countries (Moriconi-Ebrard, 1993).

When countries were colonized and settled in majority with European population, i.e., as USA (Bretagnolle et al., 2018), or even a lesser fraction as in South Africa (Baffi et al., 2018) for instance, the origin of cities is frequently associated with the development of seaports and then roads or railways networks. In these "New World" countries, the development of local market and administrative centers according to the principles of central place theory happened historically along pioneer fronts at the same time or even after the generation of the first major cities through the effect of long distance trade and political relationships. Indeed the territorial and reticular principles always are more or less mixed in the genesis of urban networks. However, although Jean Reynaud or Walter Christaller envisaged certain modalities of the evolution of urban networks, posterity has hardly retained the mention of these hypotheses, probably because their conceptions were not sufficiently based on the relational properties of cities, which will be studied by theories that assume another form of representation of urban networks.

\subsection{Emergence of network thinking through interurban competition}

It is remarkable that despite the general acknowledgement of the role of networks in urban development, very little attempt at formalizing the relationship appeared before the end of $20^{\text {th }}$ century. Lalanne (1863)'s attempt at formalizing the relationship between the size of urban centers, their distances and the newly designed railway lines is an exception A few analytical studies discussed the direction of causality between urban growth and the development of railways (see for instance in the case of France the alternative results in Pumain, 1982b; Bretagnolle, 2003; Mimeur et al. 2018; Raimbault, 2018). Indeed, physical or technical 
networks alone cannot explain urban developments and only multivariate approaches including urban complexity could help in further developing the contribution of networks to urban theory.

We must mention here a "precursor" remarkable as much for his erudition as for the complexity of his reasoning, which was totally forgotten for centuries. Giovanni Botero (1588) introduced a very comprehensive vision while exploring the "causes of the beauty and greatness" of cities (Gaudin \& Pumain, 2000; Pumain \& Gaudin, 2002). He provided a formalized verbal description of their multi-dimensional capacities and mutual adaptation in a context of fierce inter-urban competition. Giovanni Botero listed a series of factors conducive to urban growth: authority, strength, the withdrawal of population and wealth from neighboring regions, and utility, whether in terms of the convenience of the site, the fertility of the surrounding area, or the ease of access (by land and sea). Through a systematic comparison carried out since antiquity and on a global scale, drawing examples from Brazil and China as well as from Europe and Africa, he emphasizes that each of these properties is necessary, but not sufficient, for the development of a large city. By showing that natural dispositions are reinforced by human artifice, he is led to precise which specific activities, in competition with other cities, are the basis for the size of cities and under what conditions these activities function well, whether it be the residence of princely or religious powers ("the city. ...grows in proportion to power"), the exercise of justice, the relationship of which increases with the level of jurisdiction, knowledge and the necessary accompanying freedoms, industrial production or the freeing of commerce from taxes, and the development of traffic routes. It then sets out the conditions for what we would today call the "sustainability" of urban growth, in terms that recall the current formulation of dynamic models. Beyond the universal trend towards growth in human numbers, he links the growth of a city to its potential capacity ("dalla nutrivita d'esse città"), the latter being itself determined by its attractiveness, and limited by certain random disturbances (famines, plagues, wars...) and by competition from other cities. The growth of a city is thus dependent on the specialization of its trade in a product sought after by its quantity or quality (called later in the literature "comparative advantage"). It tends to be self-replicating: "the causes of production are the same as the causes of conservation", and lasts as long as justice, peace and abundance reign. The city, however, is a brake on its own growth, since its large size is causing more and more supply difficulties.

Expressed in these terms, Botero's theory of urban growth is reminiscent of the current formulation of systemic theories of cities. Can it be said that all it lacks are the equations for a dynamic model transcription?

Indeed, the notion of a system of interdependent cities has only been explicitly formulated very gradually. We can quote here the development of organicist views by a few major European geographers at the beginning of $20^{\text {th }}$ century (Pumain \& Robic, 1996). Harold Mackinder (1902) when examining the evolution of British cities describes three successive spatial and functional modes of operation: first the function of local crossroads; second, mining or metallurgical towns based on the exploitation of localized resources; third cities that specialized in more diversified functions (tourism, residence, transport, etc.) and above all, differing from the previous generations of cities: their location does not respond to a site of resources, but rather to a situation within an urban ensemble. Consequently, the expression "ensemble of cities" is no longer adequate: it is a system of interrelationships that is involved, creating "federations of cities". Without being systematic, the explanation of this evolutionary conception, inspired by a theory of the evolution of species, is based on technical modernity ("steam and electricity are 
changing our geographical conceptions", Mackinder, 1902). It underlines the change in scale of spatial organizations and their increasing complexity. Thus, urban forms are changing so that they are no longer based on the spatial continuity of the built environment but on coordinated systems of settlement, specializations and complementarities. In an article devoted precisely to the evolution of cities, Elisée Reclus (1895) has explored this urban structuring around the London conurbation, which projects not only ring-shaped suburbs around the City, but also specialized satellites. Only the spatial integration linked to the space-time contraction allows this organization. A few years later, Patrick Geddes (1915) believed that this new form of settlement organization should be called "conurbation", a term he created to designate the new "city-regions" that broke the old city-country opposition by creating vast, interconnected entities made up of several centers linked by high-density communication routes. Perhaps less acute in France, where the notion of agglomeration is sufficient to describe new forms of urbanization, geographical thinking at the beginning of the 20th century nevertheless theorized the emergence of new urban regional forms. Vidal de la Blache points out the modern trend towards metropolization (concentration of populations and activities in large cities) and the regrouping of cities, ports and industrial centers. According to him, these new phenomena of "concentration" break with the classic constraint of urban spacing. To interpret them, he constructs a notion which, borrowed from Mackinder, does not depart from the idea of the crossroads. Vidal's "nodality" is conceived as a local emergence, linked to a particular gathering of functions. In this way, the city brings together regional activities and links this productive space with its markets. The nodality of a city is the "reunion of all the auxiliaries required by commercial and industrial life" (Vidal de la Blache, 1911). It is not measured by the population, or, "still less", by the number of civil servants, and would require a distinction in the activities that fall within its scope. Typical of the dynamic "regional city" and the industrial metropolis, nodality is a characteristic of modern economic functioning.

While Vidal's work is the seed of the idea that would be expressed today as the emergence of a level of organizational complexity, stemming from the life sciences, several biological metaphors are explicitly associated with the formulation of phenomena of interdependence between cities, whether it be organic comparisons (the nervous system in Geddes, for example) or the assimilation between the workings of life and economic and social processes. The organicist metaphor proves to be particularly appropriate to these conceptions of the city, which see it as a participant in a totality. This organicist metaphor is recurrent, it has never completely disappeared. The notion of urban function used by geographers or town planners comes from this perspective, just as clearly as more obvious propositions such as statements that cities are born, live and die, or even have a soul, an identity.

\section{Systems of cities, complexity and co-evolution}

The inspiration for conceptualizing sets of interdependent cities shifted from biology towards physics during the second half of $20^{\text {th }}$ century. The expression "system of cities" appears as early as 1841, in the text by Jean Reynaud. However, the theoretical content of this notion has evolved significantly. In the 19th century, the use of this term denotes a relatively rigid organization that has a purpose and a function. The example would be the blood system or the nervous system. The interest of the notion is to emphasize the interdependencies between the parts of the system, which are between them in relations of common development or regulation, 
and which form a whole, a whole that is more than the sum of its parts. Models from physics or cybernetics disseminated later in the social sciences about settlement systems. Jean Gottmann (1947) recalled the temptation of a "social thermodynamics", which Gibbs' work at Yale in the 1910s gave rise to, and suggested that we should take inspiration from it in order to establish a methodology for analyzing interdisciplinary "crossroads".

The real transfer of the concept took place in the 1960s. In 1964, B. Berry, with his famous expression "cities as systems within systems of cities", emphasized the two relevant levels of organization and observation: on the one hand, the city, considered as a set of neighborhoods, institutions or actors in systemic relations, and on the other hand, the system of cities, organized by the principles of central place theory. Alan Pred made historical analyses of innovation diffusion and growth in systems of cities (Pred, 1973); he also scrutinized the evolution of variegated urban interactions in developed countries (Pred, 1977). In that book he identifies the notion of "city system" by applying a very general definition as "a set, national or regional, of interdependent cities in such a way that any significant change in the economic activities, occupational structure, income or population of one of the cities directly or indirectly brings about any change in the economic activities, occupational structure, income or population of one or more other elements of the whole". However, subsequent empirical research on how city systems evolve was to clarify this proposal and in particular the notion of "significant change". Indeed, it is not just any local transformation that is likely to affect the other cities in the system.

We recall here briefly how an evolutionary theory of urban systems (Pumain, 1997) emerged from that long research history. Formalizing the evolution of cities within a theory that is really embedding most of the empirical observations about their organization and evolution required roughly three logical steps. First, linking the distribution of city sizes with models of urban growth; second, linking the transformation of socio-economic profiles of interdependent cities with the diffusion of innovations and scaling laws; third, using simulation models for reconstructing these observations and testing the validity of the theoretical hypotheses on a diversity of cases.

\subsection{Distribution of city sizes and urban growth}

Recurrent observations about sets of cities over historical times brought evidence of a paradoxical persistency of a certain structural identity of a group of cities over time, despite the vagaries of demographic and economic growth. "While the urban population increases in quantity and proportion to the total population, while the number of cities and their size continue to grow, while this process is accompanied by very significant changes in productive systems and in the living and housing conditions of populations, we observe a very large persistency in the relative positions of cities in the hierarchy of sizes and a persistence of functional specialization among urban areas (Pumain, 1982a, p.7). Whereas according to Walter Christaller the statistical regularities in the distribution of city sizes coined by Auerbach (1913) and Zipf (1941) were merely "playing with numbers", an abundant literature emerged after them in connection with systemic theories and complex systems (Cottineau, 2017). Zipf's "rank size rule" raised several statistical variants that were often tested on data that lacked rigor in the definition and delineation of urban entities. The diversity of the results obtained led to misunderstandings and uninformed discussions, which I have reported on several occasions in subsequent writings (Pumain, 2012). 
On the other hand, few authors at that time had considered the model of settlement size hierarchy proposed by Gibrat (1931), according to a lognormal distribution, which has the advantage of being testable as generative process. The model in fact links the shape of the distribution of city sizes to the process of randomly distributing the growth between cities. Relying on harmonized databases of all cities and towns (defined as urban agglomerations or urban functional areas) in a territory, observed at short intervals over a fairly long period of time thanks to census data, therefore made it possible to verify both the degree of adequacy of a theoretical model of urban hierarchies and the plausibility of the growth hypotheses predicted by Gibrat's model. The process of "proportional" growth (added quantities at short time intervals are proportional to the acquired size) thus gives rise to a lognormal distribution of city sizes if urban growth rates (added quantity divided by size) are randomly distributed whatever the city size and not correlated with previous rate. Brian Robson (1973) had tested it successfully on the evolution of urban agglomerations in England and Wales during the $19^{\text {th }}$ century. He mentioned however a few slight deviations between empirical observations and the pure stochastic model, which I also observed when testing it on French data $19^{\text {th }}$ and $20^{\text {th }}$ century (Pumain, 1982a). Gabaix and Iohannides (2004) tested it on US data and many other authors since.

Although not quite perfect, the rather good quality of fit of the model made it a satisfying first approximation for summarizing the urban growth process. The contribution to urban theory was thus double: the model provides first a statistical explanation of the shape of urban hierarchies and second a better understanding of the persistency of their spatial pattern. This explanation could be admitted by geographers, but not by specialists of urban economics for whom the ranksize rule remained a "mystery" (Krugman, 1996), mainly because economists wanted to derive it from a process that would be defined at the level of individual firms and persons.

\subsection{Inferring co-evolution from comparative socio-economic change}

Admitting that a rather simple stochastic process of urban growth can explain the distribution of city sizes, with its strong inequalities and its persistence over time is a step forward in knowledge. It is a morphogenetic explanation, as the morphology of the system of cities is thus related to the dynamics of this system. However, from the point of view of geographical theory it is frustrating since in this stochastic statistical model intentional individual initiatives disappear because their result is random and cities are supposed to be independent from each other - which of course they are not. This also means taking the search for an explanation a step forward: why do cities grow all together in that way? What justifies that all well-connected cities in the same territory have on average the same growth rate over the long term, despite the large fluctuations observed in this growth spatially and over shorter periods?

Considering this leads to searching for an explanation by investigating how migrations (that represent the attractiveness of cities) relate to the jobs cities offer to the population, or how investments select cities where they locate. At certain periods, the fastest growing cities, which are the most attractive, are those where job creating and income-generating activities are developed. Geographers have a long tradition of classifying cities according to their activities and skills and thus defining urban functions, or functional specializations (Berry \& Smith 1972; Pumain \& Saint-Julien, 1976). Multivariate analyses provide a synthetic description of the most frequent associations and exclusions of activities in cities. Among contemporary cities, a major difference still separates two types of cities, those with predominantly manufacturing bases and 
those oriented towards services, inherited from the highly distinctive specializations created with the industrial revolution of $19^{\text {th }}$ century. A secondary differentiating factor represents traces of recent (after 1950) changes improving technologies and practices (so-called knowledge intensive activities) among industrial and tertiary specializations, in France as in the US (Paulus \& Vacchiani-Marcuzzo, 2015) as well as in China (Swerts, 2016). Looking at the relative stability or slow evolution of that fundamental structure over a few decades, we found a surprising parallelism in the trajectories of individual cities: the qualitative and quantitative changes occurring in the social and economic composition of urban populations were almost the same in every city (Pumain \& Saint-Julien, 1978; Paulus \& Vacchiani-Marcuzzo, 2015). This incremental and distributed process of socio-economic change contributes to a kind of simple homothetic translation of the former hierarchical and functional structure of the urban system.

A constantly renewed flow of innovations modifies the socio-economic profile of cities. Many socio-economic changes, specific to a city, do not affect the structure of the system, because they are not sufficiently persistent from one period to the next, they are simple fluctuations that do not alter the relative place of cities in the system if they occur when the system is on a stable trajectory. The change in structure occurs when one of these fluctuations persists and increases to such an extent that it permanently alters this position, most often for several cities at the same time, often associated with an innovation wave and the development of a new specialization. In such cases, there is a "bifurcation" in the history of the system. Such an evolution is comparable to that described in physics as "self-organizing open systems" (Allen, 1997; Wilson, 1970). Behind the structuring of these systems according to an architecture that is identifiable because it is persistent, there is no network operator, nor an explicit political or economic purpose, which could be described in terms of a function to be optimized. In other words, systems of cities are not in equilibrium at a given moment, they transform under the action of internal and external dynamic processes. Their structure is the product of this evolution.

The evolutionary theory of urban systems (Pumain, 1997) includes in a unified process the organizational duality between the hierarchical organization of the systems of cities controlling and serving the territory on the one hand, and their networking for the exercise of various specialized functions on the other hand. It links the structure of systems of cities with the process of diffusion of innovations. When a city (usually a large one) adopts an innovation, it is very quickly imitated in other cities and this process is filtering down the urban hierarchy. Cities' adaptive power to change depends on their relative position in the system in terms of resources, both site-related and accumulated. The Swedish geographer Torsten Hägerstrand (1952) early formalized that observation and called this process a "hierarchical diffusion of innovation". A large number of authors have illustrated the link between the speed of adaptation to change and previous accumulation (summarized by the size of cities, their financial power and skills of their inhabitants and institutions) and illustrated the hierarchical diffusion process of innovations in urban systems (Robson, 1973; Pred, 1973 and 1977).

Compared to the simplistic description of urban growth provided by Gibrat's model, these results attain several gains in explanation. First, it is not because they are statistically independent entities that cities grow roughly at the same rate, but on the contrary because they share the same kind of transformation of their economic and social profiles, as being part of a territory under common laws and societal regulations and processes. This is likely to happen because of the multiple connections ensuring a rapid communication of information between 
cities. Second, the Gibrat's model when completed by including growth impulses from innovation waves and their hierarchical diffusion within the system of cities (Favaro \& Pumain, 2011) helps to better understand the recurrent deviations that were observed between empirical data on urban growth and Gibrat's stochastic model, i.e. a slight positive correlation between growth rates and city size (at the beginning of each innovation wave) and a persistency of high or low growth rates in the same cities over some periods of time. This also provides an understanding of the bifurcations in the trajectories of individual cities that are created by the major functional specialization, successively amplifying urban growth then urban decline according to the stage in the corresponding product cycles.

We were able to use that knowledge for developing an interpretation, which is better anchored in geographical urban theory, of the new frame of analysis proposed under the label of "scaling laws" by physicists (Bettencourt et al., 2007). Instead of imagining an urbanization process where largest cities would simply be a replication of smaller ones constrained by universal power laws ${ }^{3}$, we explain the level and observed variations in values of the exponents of urban scaling laws according to the stage of development of the considered urban attributes in the urban system (Pumain et al., 2006 and 2009). Exponents of non-linear relationships between an urban attribute and city size are above 1 during the first stage of adoption of innovation in the urban system, when they are captured by and concentrate in the largest cities, and below 1 when they withdraw in smaller towns of cheaper land rents and wages after their stage of wide diffusion all over the system. Over time, the exponent values evolve according to this theory (Paulus 2004; Paulus \& Pumain 2011; Finance \& Swerts 2020). Scaling laws are thus convenient instruments for expressing urban centralities at different aggregated levels of urban settlements (Cottineau et al., 2017) or for detecting urban agglomeration economies (Cottineau et al., 2019).

Thus, starting from an interpretation of a temporal multivariate analysis, we have made a "discovery" that was later confirmed with a series of different investigations. To summarize that discovery: size inequalities and qualitative socio-economic differences between cities are traces of their co-evolution (which is an interactive and proactive adaptation with feedbacks to the innovations they create) within interconnected systems of cities. The expansive trend that characterizes these systems in a quantitative way (growth in population and wealth) and qualitatively (through technological and societal innovation) is an essential driving force of their structure and evolution. Elements of such a theoretical explanation were already there in urban geography, especially in the theory of hierarchical diffusion of innovations (Hägerstrand, 1952). The novelty also comes from the simulation models enabling to test the hypothesis of the theory.

\subsection{Reconstructing evolutionary trajectories for testing the evolutionary theory of urban systems}

The evolutionary theory of urban systems includes hypotheses on the generating processes that explain their structure and possibly allow predicting their future evolution. This conception can be tested on empirical data about past evolution using mathematical and computational concepts and models proposed by the science of complex systems that has been developing in recent decades. The principle is that interactions between cities explain their trajectory and the structure of the system of cities. Multi-agent models are best suited to represent the exchanges

\footnotetext{
${ }^{3}$ This is not a well-adapted description since systems of cities are not ergodic (Pumain 2012).
} 
between cities, differentiated according to their functions and spatially distributed. We briefly now summarize this research process, which originated in creating a whole family of SIMPOP models ${ }^{4}$.

The last thirty years enriched the theories of self-organisation in physics (Prigogine, 1996; Haken, 1977), evolution of living species in biology and adaptive cognitive systems in economy or social networks (Arthur, 1994; Allen, 1997; Weidlich, 2006). Our representations of system dynamics changed, especially by emphasizing the conditions of emergence of new structures from local interactions between adapting individuals. The main epistemological questions have therefore shifted from the autonomy of systems relative to their environment, towards the identification of attractors governing their dynamics, and lastly to their capacity of innovation within a context of uncertain and changing rules of social interactions. Compared to these earlier representations of self-organisation in models, the actual notion of emergent properties refers to a more explicit modelling of individual behaviour and interactions, usually in agentbased models or in multi-agent systems. Emergent properties appear at a higher level of aggregation than the original description of the system. They consist most of times in the formation of a structure at the macro level (which may arise in an unexpected way from the individuals and their interactions as they are described in the model), and more rarely consist in the appearance of a true novelty, which was not expected at all, but can be confirmed afterwards in empirical testing. Ideally, this last case would be the prediction of a social innovation.

Multi-agents systems (MAS) are especially useful as simulation tools for modelling a dynamics, when it is essentially explained by the heterogeneity of individual features and their interaction. They enable the modeller to associate qualitative and quantitative rules, and to integrate several levels of organisation as well as diverse time scales and dynamics relationships. They are used in natural, social or cognitive sciences, as artificial laboratories (in silico) for observing the behaviour of agents at an individual or collective level, and analysing the evolution of the structures which emerge at a macro-level (Ferber, 1995). They appear as a reasonably promising technique for simulating geographic worlds, mainly because of their ability to consider the environment of a system, their acceptance of a wide conceptual diversity of agents (allowing for multi-level analysis) and their flexibility regarding interaction rules, especially in spatial relationships.

MAS are much more flexible than differential equations for simulating spatial and evolving interactions, including quantitative and qualitative effects (Pumain \& Sanders, 2013). Through the definition of rules at individual level, they can reproduce the circulation of information between cognitive and decision-making agents. They simulate at the upper level the emergence of collective or aggregated structures, which can be tested statistically. The rules can be adapted for varying space and time scales of interaction under the course of history. Of course, multiagents systems do not solve the problem of choosing a "good" theoretical representation. A first application to geography was the SIMPOP model (Bura et al., 1996; Sanders et al., 1997), which used MAS for simulating the emergence of a functionally differentiated system of towns and cities from an initial more or less homogeneous rural settlement system, over a duration of some 2000 years. This model differs from most of MAS in two aspects: its agents are immobile, as

\footnotetext{
${ }^{4}$ http://www.simpop.parisgeo.cnrs.fr/home
} 
they represent places in geographical space, even if their interactions are affected by the technical innovations in the communication systems and the increasing level of urban resources that modify the relative situation of elementary cities in the network of their relational space. Second, as SIMPOP is a model of interactions between territories (aggregated geographical objects), the "behaviour" of such agents is not reducible to the behaviour of individual persons, for instance as in models of cognitive economy. Compared with the difficulty of representing spatial interactions with parameters such as in mathematical models using systems of differential equations, MAS models enable to differentiate different types of spatial interactions processes. Within the SIMPOP model, inter-urban interactions for market activities are freely competing but constrained by a distance decay model of gravity type, while administrative functions levy taxes in fixed spatial subdivisions. Specialized activities develop interactions according to specific types of networks that may reach long distance and cross national boundaries. These longer distance and more freely distributed interactions are linked to the location of resources in the case of manufacturing and to resort amenities in the case of tourism for instance.

Anderson et al. (2003) use an algorithm generating «scale-free » networks. This corresponds to a class of growing networks whose node degrees are power-law distributed because of a rule of preferential attachment - according to a growth process similar in its consequences to Gibrat's model (Barabasi, 2002). In their model, the nodes of the network represent pieces of land which over time become more and more connected by edges representing exchanges of goods and services (the result of this trade is in fact simulated by a trade benefit or financial investment directed from one node to another). The model proceeds by adding new links between already developed nodes, with a probability of this occurring that is proportional to the relative size of the node in the total number of nodes, and by selecting new nodes. The mean probability of developing existing nodes is significantly higher than that relating to the development of new nodes. Spatial rules are added to specify this selection process, according to hypotheses about a distance-decay interaction model. Thus, this model is designed to simulate the urbanization process on the intra-urban scale, or the formation of urban hierarchies, or both. In any event, the concept of "scale-free" networks, or "small worlds", seems well adapted to the simulation of urban systems, since they reveal the hierarchical structure that emerges in progressively constructed networks.

What are interurban interactions in the SIMPOP models? As our intention is to simulate the development of urban systems that include a large number of towns and cities, it would be unrealistic to think of interactions as "real" flows of exchanged goods, people or information. The interactions that are simulated in the model are not these "first order" interurban exchanges, but more abstract, "second order" interactions, which represent an interpretation of the effect of concrete flows on the relative dynamics of cities. For example, the urban functions are essential attributes of the cities. They do not give an exhaustive representation of the economic profiles of the cities, since they are attributed only to the cities having developed a major specialisation in a particular sector of activity during the corresponding innovation cycle. In a similar way, the exchange of products and resources among cities on the "market place" (cities selling and buying according to their level of supply and demand) does not reflect the totality of the urban economy but only the specialised part of the interurban market, the one that is likely to give rise to urban growth differentials. 
Our model is a geographic model, in the sense that spatial interaction are supposed to reflect the power of cities in terms of range of influence of their activities and support for new developments from their access to more or less extended markets. Three types of spatial interactions are distinguished for reflecting the most frequent types of interurban exchanges, linked to different constraints. Proximity constrained interactions are representative of many activities for which the distance between supply and demand is an essential constraint, they are the rule for all central place functions, whatever their level and range, and even if that spatial range is increasing over time; under that rule, the probability of exchanges are distributed according to a model of gravity type. Territorially constrained interactions are limiting a city's influence within boundaries, regional of national. They correspond to all types of administrative or political activities and the interaction rule is modulated according to the nature of the activity, for instance, a capital can levy taxes in an exhaustive way on all cities belonging to its region or state, whereas in the case of other activities this rule can attribute only a preference for a territorial market. Interactions within specialised networks are free from distance constraints, even if exploring them for developing new markets along this line may have differential costs according to the distance. Long distance trade, maritime transport, part of tourism activities, or manufacturing industry, are following this type of spatial interaction rule.

The results of experiments with this model provided further advances in explaining the evolution of systems of cities, proving the importance of urban networks in generating more urban growth. Actually, until nowadays, the observed historical major dynamic trend leads to an increasing hierarchization: the inequalities in city sizes are becoming larger than those that would be predicted with Gibrat's model, contradicting the theories predicting counterurbanization (Berry, 1976). A new discovery that "global cities may exist since the Middle Age" also emerged since the cities that are at the head of urban hierarchies always expand a significant part of their interactions beyond the boundaries of their own system (Bretagnolle \& Pumain, 2010). We have verified in further studies including as well the BRICS countries that "metropolisation" and "simplification from below of urban hierarchies" (leading to "shrinking cities") are common dynamics trends observed in several systems of cities in the world (Pumain et al. 2015).

The research program GeoDiverCity ${ }^{5}$ paved the way for developing a new method of building simulation models aiming at taking into account not only the general urban dynamics for reconstructing common stylized facts but as well the major historical features that distinguish regions of the world. The MARIUS model designed by Clementine Cottineau and Paul Chapron with the help of the OpenMOLE simulation platform intended to reconstruct the trajectories of cities within the boundaries of the territorial system of the former USSR (Cottineau, 2014). In parallel, the authors invented an incremental method for model building: from a hierarchy of factors explaining the differential urban growth that was revealed by statistical analysis of the observed trajectories of individual cities. They implemented first the simplest and more generic model of urban growth (i.e. a Gibrat's stochastic model without spatial interaction) then introduced more sophisticated mechanism of constraints on urban growth as well as some specific environmental conditions (Cottineau et al., 2015). At each step, the computed deviation between expected shape of urban hierarchy and typology of urban trajectories and the computed ones helped to measure the retro-predictive capability of the model. For instance, in that case it was important to introduce not only resource location for generating functional specialization

\footnotetext{
${ }^{5}$ ERC advanced grant GeoDiverCity 2011-2016 (PI Denise Pumain)
} 
but as well the political decision of large investments in these urban areas. A new geographical modelling framework is thus proposed, which operates at different levels of precision, according to an adjustable focus evaluating the degree of specificity of a particular evolution in a generic dynamic, for a given granularity of description (Cottineau et al., 2015).

The OpenMOLE simulation platform allows the integration of sophisticated model validation processes, including genetic algorithms and access to parallel grid computing. We have been able to acquire more certainty in the quality of parameter estimation for a generic model, SimpopLocal (Schmitt 2014) dedicated to the emergence of a system of cities during some 4000 thousand years after Neolithic with the help of the SimProcess platform developed by Sébastien Rey-Coyrehourcq (2015). Compared to the few hundred simulations that were available when estimating with trial and error "by hand" methods in the former experiments with the first Simpop models, it was possible to develop an almost exhaustive exploration of the space of parameters, through some 500 million replications of the same model (Schmitt et al., 2015). The theoretical hypotheses thus tested and assumed to lead to the emergence of a system of cities based on interactions propagating innovations between population centers could be considered not only as sufficient, but also as necessary to reconstruct an urban hierarchy and a right diversity of urban trajectories. A new procedure for the rigorous exploration of the behaviors of a model called "calibration profile" was developed for that precise purpose (Reuillon et al., 2015). Such an outcome is important for the humanities and social sciences because it opens the door to providing proof when answering questions about complex social processes.

\section{Towards multi-level urban networks}

While concluding recently a book that we edited on world urbanization (Rozenblat et al., 2018) we made a plea for "multi-scalar urban policies". Indeed, the available urban knowledge still appears as too fragmented between a variety of disciplines for efficiently enough inspiring policies. It is also not yet connecting well the accumulated knowledge from the past with the new "urban sciences" (Batty, 2013). It also remains difficult to establish a sound reasoning at both levels of individual cities and at the level of systems of cities. The construction of simulation models including spatial interactions and networks has made considerable progress, particularly in terms of technical validation (Pumain \& Reuillon, 2017), but remains limited by the lack of precise information on the interactions between the different levels of urban systems. Until very recently the lack of data observed at individual level hampered a real consideration of inter-individual relationships in urban modeling.

Probabilistic reasoning in statistical and simulation models takes into account the material impossibility of knowing at any given moment the exact position and state of all the elements that make up the system and denotes the existence of several levels of observation in the system. With regard to cities, the "micro" level corresponds to that of the individual or collective stakeholders that make up the social environment of a city, who are connected and mutually informed of their actions, and who compete with those of other cities to capture the profits associated with the exploitation of innovations. The routes and relationships that unite the cities in a system are also social networks through which information flows. Some of these networks organize hierarchically, de jure, (administration) or de facto (distribution), while others not, and the possibility of their capture by any city in the system is not excluded a priori. Successful 
specialization at a given moment is the result of exploiting the initial advantage conferred by the early adoption of an economic, social or political innovation that is bound to develop. The actors know about structure of the urban network (hierarchical form and specializations) and can use it to comply with it or to challenge it. In spite of the diversity of the stakeholders' personalities, motivations and actions, the aggregation of their behavior produces regularities that can be represented at the level of the evolution of a city as well as that of the system of cities, with a "random" factor, a degree of unpredictability of varying importance corresponding to the ignorance in which one finds oneself of the decisions taken by the stakeholders.

Research is still lacking to articulate the form taken by local social networks (within a city) to that of cities as a whole. In particular, it is not clear what makes a local "synergy", a particular form of social relations in a city, effective, which some believe would facilitate its adaptation to change. The exercise is tempted with a real success for specific networks as investment chains between firms and their subsidiaries (Rozenblat, 2010). That type of data greatly enhances the knowledge about the functioning of the emerging system of cities at global scale.

Progresses in this direction are now anticipated from several directions: the expanded computing capacity and new algorithms enable to handle more precisely the statistical treatment and visualization of the structure and evolution for very large networks (Rozenblat and Melançon 2013). Concepts and methods for social network analysis rapidly develop as demonstrated in a few previous works developing applications to cities (Pflieger and Rozenblat 2010; Neal 2013) as well as in several chapters of the present book. Sophisticated simulation methods help in identifying the key processes that connect the communication networks and the development of systems of cities (Raimbault, 2018). The technical concerns for developing smart cities appear in a variety of research about better-informed communication systems, at local (Keyvan-Ekbatani et al., 2012) or global scale (Graham, 1999). Massive data extracted from smart phones traces, exchanges in social networks collected from the web (as Twitter, Facebook or Weibo, see for instance Fang et al. 2020) also are promising researches but now often lack of enough substance in the attributes they inform for being used efficiently as proxies for measuring interurban interactions. Interestingly enough, many lessons about the importance and variety of urban interactions may be taken from the gigantic experiment of their drastic reduction worldwide and at all geographical scales during the recent epidemics of Covid19. A first exploration of these data is made relying on a simulation model that consider spatial interactions of a fractal form at all geographical levels (Abbasi et al. 2020).

We illustrate the evolutionary functioning of implicit or materialized inter-urban networks in figure 1 according to three major historical eras separated by two major transitions (figure 1). About 6000 thousand years ago, at the time cities emerged some three thousand years after agriculture was invented, urban growth started through sharing with close settlements technical and societal inventions. That enabled much higher densities and social diversification within cities through the multiplication of social interactions facilitated by higher densities, but their development was hampered by many hazards of their environment due to natural catastrophes or war predations and destructions ${ }^{6}$. Prepared long before but exploding after year 1800 with the industrial revolution emerges a period of apparently free development of urban networks sustained by an enormous gain in energetic power and diversification of manufacturing production that was accompanied with an expanding urbanization all over the world. Growth

\footnotetext{
${ }^{6}$ The chapter by E. Bogumil and C. Chase-Dunn in this book well document urban settlements at that period
} 
in individual income and life expectancy characterize in average this period during which cities become the habitat of a major part of humanity and the way of living of reference for all. However, that huge development was made at the expense of planetary resources that are not priced at the level of their real value. In a metaphoric way, one estimates that three to six planets would be necessary to ensure raising the consumption level of world population to that of actual Europe or USA. Moreover, the environmental degradation and the climatic change have raised concern about a necessary ecological transition that would lead to more sober consumption and a better care of the quality of interactions between human activities and natural resources. For succeeding in that transition, the existing systems of cities fortunately provide their diversity of already built networks. They supply their numerous and variegated channels for conveying the top down incentives, from international or national agencies, for adopting new regulations, as well as circulating bottom-up the locally generated initiatives and sharing adapted alternative views for developing really cities that will be smart to their inhabitants.

\section{Figure 1 Interurban networks within evolutionary theory of systems of cities}

\section{Three stages in the evolution of urban systems (series of Simpop models)}

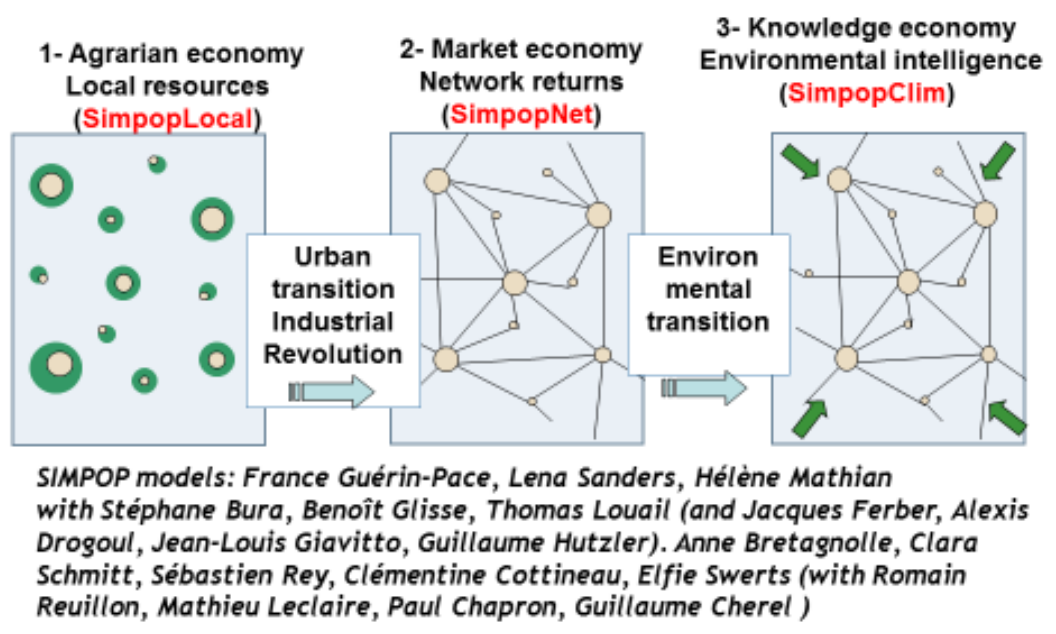

\section{Conclusion}

Systems of cities are a form of adaptation to change generated by human societies, an invention that is generally not perceived as technical, but which is the result of historical processes of self-organization. Several disciplines in social sciences conceptualize each aspects of their intrinsic complexity. Economically, urbanization is reflected in the accumulation of capital, knowledge and wealth, in attracting firms in multiplying networks that accompany technological creation and innovation. Geographically urbanization articulates settlements of diverse sizes and functions for handling most of daily interactions within diversified and hierarchized systems of cities that efficiently connect at higher space and time scales different economies and cultures. Socially, urbanization promotes the diversification and increasing sophistication of institutional and political forms of organization, including an intensification and refinement of the social division of labor, partly unifying but also deepening inequalities in 
access to wealth, well-being, education and knowledge. Culturally, urbanization, often held to be synonymous with "civilization", catalyzes the evolution of collective mores and cognitive representations through intermixing, hybridization and education, opening up prospects for a better knowledge of diversity and greater acceptance of the Other.

All these trends seem to represent a progress for humankind, as translated at the individual level in the historical elevation of synthetic indicators such as average income, the human development index, or healthy life expectancy. However, we now know that this evolution also marks the irruption of human activity in energy balances and the functioning of the earth's ecological system, which leads to the proposal of a new stratum, known as the Anthropocene, in the geological ages. Cities have accompanied and sustained the current over-consumption of planetary resources. The increasing scarcity of available materials and energy sources, the disasters caused by the major climate changes that have been underway for at least two centuries, and a full variety of global threats also seem to be a result of the very success of urbanization.

As revealed by the recent pandemics of Covid19, and following the lockdown having stopped for a while a large fraction of social interactions for more than half of the world population, cutting the networks that connect people within and between cities obviously reduce not only the propagation of an epidemics but as well the economic efficiency of cities. Thus, networks must be a significant part of urban theories explaining their functioning and development.

\section{References}

Abbasi, M., Bollini, A. L., Castillo, J. L. B., Deppman, A., Guidio, J. P., Matuoka, P. T., ... \& Varona, A. R. P. (2020). Fractal Signatures of the COVID-19 spread. Chaos, Solitons \& Fractals, 110119.

Allen P. (1997), Cities and regions as self-organizing systems: models of complexity. Amsterdam, Gordon and Breach

Andersson, C., A. Hellervik, K. Lindgren, A. Hagson, and J. Tornberg (2003). The urban economy as a scale-free network. Physical Review E 68(036124).

Auerbach F. (1913). Das Gesetz der Bevölkerungskonzentration. Petermans Mitteilungen, 59, 1, 74-76.

Baffi, S., Turok, I., and Vacchiani-Marcuzzo, C. (2018). The South African Urban System, in Rozenblat C. Pumain D. Velasquez E. (eds) International and Transnational perspectives on Urban Systems (pp. 285-314). Springer, Singapore.

Batty, M. (2013). The new science of cities. MIT Press.

Beckmann M.J. and MacPherson J.C., (1970). City size distribution in a central place hierarchy. Journal of Regional Science, 10, 1, 25-33.

Beguin H. (1988). La région et les lieux centraux, in Ponsard C. (ed), Analyse économique spatiale, Paris, PUF.

Beguin H.and Thisse J. (1979). An axiomatic approach to geographical space. Geographical Analysis, 11, 4, 325 341.

Berroir S. Cattan N. Dobruszkes F. Guérois M. Paulus F. and Vacchiani-Marcuzzo C. (2017) French urban systems : a relational approach. Cybergeo, European Journal of Geography, 807.

Berry B.J.L. (1964). Cities as systems within systems of cities, Papers of the Regional Science Association, 13, 147-163.

Berry, B. J. L. 1976. Urbanization and counter-urbanization (Vol. 11). Sage Publications. 
Berry B. J. L. and Pred, A. (1965), Central Place Studies: A Bibliography of Theory and Applications. Philadelphia, Regional Science Research Institute.

Berry B.J.L. and Smith K.B. (1972). City classification handbook. Wiley Interscience.

Bettencourt, L. M., Lobo, J., Helbing, D., Kühnert, C., and West, G. B. (2007). Growth, innovation, scaling, and the pace of life in cities. Proceedings of the National Academy of Sciences, 104(17), 7301-7306.

Bird, J. H. (1973). Of central places, cities and seaports. Geography, 105-118.

Botero G. (1588). Delle cause della grandezza et magnificenza delle città. Tre libri. New edition in 1598 inside the book "La Ragion di Stato" (7th ed.) in Venice, and a cura di Luigi Firpo, Unione Tipografico Editrice Torinese in 1948, pp. 341-409.

Braudel F. (1979). Civilisation matérielle, économie et capitalisme (XVe-XVIII ${ }^{e}$ siècle), Paris, Armand Colin, 3 vol.

Bretagnolle A, (2003). Vitesse des transports et sélection hiérarchique entre les villes françaises, Données urbaines, 4, 309--323

Bretagnolle A., Pumain D., Rozenblat C. (1998), Space-time contraction and the dynamics of urban systems, Cybergeo : European Journal of Geography, 61.

Bretagnolle A., Pumain D. (2010). Simulating urban networks through multiscalar space-time dynamics (Europe and United States, 17th -20th centuries), Urban Studies, 47, 13, 2819-2839.

Bretagnolle, A., Paulus, F., Kim, S., \& Vacchiani-Marcuzzo, C. (2018). The US Urban System, in Rozenblat C. Pumain D. Velasquez E. (eds) International and Transnational perspectives on Urban Systems (pp. 69-98). Springer, Singapore.

Bura S. Guérin-Pace F. Mathian H. Pumain D. Sanders L. (1996). Multi-agent systems and the dynamics of a settlement system. Geographical Analysis, 2, 161-178.

Camagni, R. P. (1993). From City Hierarchy to City Network: Reflections About an Emerging Paradigm, in T. R. Lakshmanan and P. Nijkamp (eds.), Structure and Change in the Space Economy: Festschrift in Honor of Martin J.Beckmann, New York: Springer-Verlag, 66-87.

Christaller W. (1933). Die Zentralen Orte in Süddeutschland : eine Ökonomisch-Geographische Untersuchung Über die Gesetz Massigkeit der Verbreitung und Entwicklung der Siedlungen mit Städitschen Funktionen, Fischer Verlag, Jena.

Cottineau, C. (2017). MetaZipf. A dynamic meta-analysis of city size distributions. PloS one, 12(8).

Cottineau, C., Hatna, E., Arcaute, E., \& Batty, M. (2017). Diverse cities or the systematic paradox of Urban Scaling Laws. Computers, environment and urban systems, 63, 80-94.

Cottineau, C., Finance, O., Hatna, E., Arcaute, E., \& Batty, M. (2019). Defining urban clusters to detect agglomeration economies. Environment and Planning B: Urban Analytics and City Science, 46(9), 1611-1626.

Dickinson R. E. (1934). The Metropolitan Regions of the United States. The Geographical Review, 23, p. 278291.

Ducruet, C. (2008), Typologie mondiale des relations ville-port. Cybergeo, European Journal of Geography, 417.

Ducruet, C., Cuyala, S. and El Hosni, A. (2018). Maritime networks as systems of cities: The long-term interdependencies between global shipping flows and urban development (1890-2010). Journal of Transport Geography, 66, 340-355.

Fang, C., Yu, X., Zhang, X., Fang, J., \& Liu, H. (2020). Big data analysis on the spatial networks of urban agglomeration. Cities, 102, 102735.

Favaro J.-M. Pumain D. (2011). Gibrat Revisited: An Urban Growth Model including Spatial Interaction and Innovation Cycles. Geographical Analysis, 43, 3, 261-286.

Ferber J. (1995). Les systèmes multi-agents : vers une intelligence collective. InterEditions.

Finance O. and Swerts E. (2020). Scaling laws in urban geography. Linkages with urban theories, challenges and limitations, in Pumain D. (ed.) Theories and Models of Urbanisation. Springer, Lecture Notes in Morphogenesis, 67-96. 
Fletcher R. (1986). Settlement Archaeology: World-Wide Comparison. World Archaeology, 18, 1, p. 59-83.

Fujita M., Krugman P., Venables A.J. (1999). The spatial economy: cities, regions and international trade. New York, Wiley.

Gabaix X. Iohannides Y.M. (2004). The evolution of City size distributions, in Henderson V. and Thisse J.F., Handbook of Regional and Urban Economics, North Holland, chap.53.

Gaudin J.P. and Pumain D. (2000). Quelques métaphores au miroir des analyses spatiales : réseaux de villes et réseaux de pouvoir. Revue européenne des Sciences sociales, 117, 105-119.

Gibrat R. (1931). Les inégalités économiques. Paris, Sirey.

Graham, S. (1999). Global grids of glass: on global cities, telecommunications and planetary urban networks. Urban Studies, 36(5-6), 929-949.

Hägerstrand, T. (1952). The propagation of innovation waves. Lund Studies in Geography: Series B, Human Geography, 4.

Hoyt, H. (1961). The utility of the economic base method in calculating urban growth. Land Economics, 37(1), 51-58.

Keyvan-Ekbatani, M., Kouvelas, A., Papamichail, I., and Papageorgiou, M. (2012). Exploiting the fundamental diagram of urban networks for feedback-based gating. Transportation Research Part B: Methodological, 46(10), 1393-1403.

Kohl J.G. (1841). Der Verkehr und die Ansiedelungen der Menschen in ihrer Abhängigkeit des Gestaltung der Erdoberfläche, Dresden/Leipzig, Arnold.

Krugman, P. (1996). Confronting the mystery of urban hierarchy. Journal of the Japanese and International economies, 10(4), 399-418.

Lalanne L. (1863). Essai d'une théorie des réseaux de chemin de fer, fondée sur l'observation des faits et sur les lois primordiales qui président au groupement des populations, Comptes rendus des séances de l'Académie des sciences, t. 57, 2e semestre, 206-210.

Lepetit B. (1988). Les Villes dans la France moderne (1740-1840), Paris, Albin Michel, 490 p.

Liu L. (1996). Settlement patterns chiefdom variability and the development of early states in North China. Journal of Anthropological Archaeology, 15, 3, p. 237-288.

Mackinder H.J. (1890). The physical basis of political geography, Scottish geographical magazine, VI, 78-84.

Marcus J. and Sabloff J. A. (eds) (2008). The Ancient City. New perspectives on Urbanism in the Old and New World. SAR Press, $405 \mathrm{p}$.

Marshall A. (1890). Principles of Economics. MacMillan, London.

Mimeur C., Queyroi F., Banos A., Thévenin T., (2018). Revisiting the structuring effect of transportation infrastructure: An empirical approach with the French railway network from 1860 to 1910, Historical Methods: A Journal of Quantitative and Interdisciplinary History, Taylor \& Francis (Routledge), 2018, 51 (2), pp.65-81

Moriconi-Ebrard F. (1993). L'urbanisation du monde depuis 1950. Paris, Anthropos.

Neal, Z. P. (2013). The connected city: How networks are shaping the modern metropolis. Routledge.

Ozouf-Marignier M.-V., (1989). La formation des départements. La représentation du territoire français à la fin du $18 \grave{e ̀ ~ s i e ̀ c l e, ~ P a r i s, ~ E d i t i o n s ~ d e s ~ H a u t e s ~ E t u d e s ~ e n ~ S c i e n c e s ~ S o c i a l e s . ~}$

Paulus, F. and Pumain, D. (2011). Salaire et hiérarchie urbaine, in Pumain D. Mattei M.-F. (coord.) Données urbaines, 6, 205-216.

Paulus F. and Vacchiani-Marcuzzo C., (2015). Knowledge economy and competitiveness: Economic trajectories of French cities since the 1960's, in A. Cusinato, A. Philippopoulos-Mihalopoulos (eds), Knowledge creating Milieus in Europe. Firms, Cities, Territories, Heidelberg, Springer, pp 157-170.

Peris, A., Meijers, E., \& van Ham, M. (2018). The evolution of the systems of cities literature since 1995: schools of thought and their interaction. Networks and Spatial Economics, 18(3), 533-554. 
Pflieger, G., \& Rozenblat, C. (2010). Introduction. Urban networks and network theory: the city as the connector of multiple networks. Urban Studies 47, 13.

Pirenne H. (1925). Les villes du Moyen-Âge. Paris, PUF.

Ponsard C. (1977). Hiérarchie des places centrales et graphes-flous. Environment and Planning A, 9, 1233-1252.

Pred A. (1973). Urban growth and the circulation of information: The United States system of cities, 1790-1840. Cambridge (Mass.), Harvard University Press.

Pred A. (1977). City systems in advanced societies. London, Hutchison.

Pumain D. (1982a). La dynamique des villes. Paris, Economica.

Pumain D. (1982b), Chemin de fer et croissance urbaine. Annales de Géographie, n507, 529-550.

Pumain, D. (1992). Urban Networks versus Urban Hierarchies? Environment and Planning A 24, 1377-1379.

Pumain D. (1997). Vers une théorie évolutive des villes. L'Espace Géographique, 2, 119-134.

Pumain D. (2004). Scaling laws and urban systems. Santa Fe Institute, Working Paper n04-02-002, 26 p.

Pumain D. (2006), Alternative explanations of hierarchical differentiation in urban systems, in Pumain D. (ed.) Hierarchy in natural and social sciences. Springer, Methodos series, 3, 169-222.

Pumain D. (2012). Urban systems dynamics, urban growth and scaling laws: the question of ergodicity, in J. Portugali and H. Meyer, with E. Stolk and E. Tan, Eds. Complexity Theories of Cities Have Come of Age: An overview with implications to urban planning and design. Springer, Heidelberg, Berlin, 93-106.

Pumain D. and Saint-Julien T. (1976). Fonctions et hiérarchie dans les villes françaises. Annales de géographie, 470, 385-439.

Pumain D. and Saint-Julien T. (1978). Les dimensions du changement urbain. Paris, CNRS.

Pumain D. and Robic M.C. (1996). Théoriser la ville, in Derycke P.H. Huriot J.M. Pumain D. (eds), Penser la ville, théories et modèles. Paris, Anthropos, chap. 4, 107-161.

Pumain D. and Gaudin J.-P. (2002). Systèmes de villes et pouvoir. L'analyse de Giovanni Botero à l'époque de la Renaissance. Cybergeo, European Journal of Geography, 227, 19 p.

Pumain, D., Paulus, F., Vacchiani-Marcuzzo, C., and Lobo, J. (2006). An evolutionary theory for interpreting urban scaling laws. Cybergeo: European Journal of Geography, 343.

Pumain, D., Paulus, F., \& Vacchiani-Marcuzzo, C. (2009). Innovation Cycles and Urban Dynamics. In: Lane, D., Pumain, D., van der Leeuw, S. and West GB. (eds). Complexity perspective in innovation and social change, Methodos series, Dordrecht: Springer, 237-260.

Pumain D. Sanders L. (2013). Theoretical principles in inter-urban simulation models: a comparison. Environment and Planning A, 45, 2243-2260.

Pumain D., Swerts E., Cottineau C., Vacchiani-Marcuzzo C., Ignazzi A., Bretagnolle A., Delisle F., Cura R., Lizzi L. and Baffi S. (2015). Multi-level comparison of large urban systems. Cybergeo, European Journal of Geography, 706.

Pumain D. Reuillon R. (2017), Urban Dynamics and Simulation Models. Springer, International. Lecture Notes in Morphogenesis, $123 \mathrm{p}$.

Pumain D. (ed.) (2020). Theories and Models of Urbanisation. Springer, Lecture Notes in Morphogenesis.

Pumain D, Torre A., 2020, Regional science: economy and geography in France and French-speaking countries. Papers in Regional Science; 1-21

Raimbault J. (2018). Modeling the co-evolution of cities and networks. arXiv preprint arXiv:1804.09430.

Reclus E. (1895). The evolution of cities, The Contemporary Review, 67, 2, 246-264.

Renfrew C. (1975). Trade as action at a distance: question of integration and communication, in Sabloff A. and Lamberg-Karlovsky C.C. (eds): Ancient civilization and trade. Albuquerque, University of New Mexico Press, 359. 
Renfrew C. and Poston T. (1979). Discontinuities in the endogenous change of settlement pattern, in: Renfrew C. \& Cooke K.L. (eds), Transformations: Mathematical approaches to culture change. Academic Press, 437-461.

Rey-Coyrehourcq, S. (2015). Une plateforme intégrée pour la construction et l'évaluation de modèles de simulation en géographie. Doctoral dissertation, Paris 1-Panthéon-Sorbonne.

Reymond H. (1981), Une problématique théorique, in Isnard H., Racine J.-B., Reymond H. Problématiques de la géographie, Paris PUF.

Reynaud J. (1841). Villes, dans Encyclopédie nouvelle, Paris, éd. par C. Gosselin, t. VIII, 670-687.

Reuillon, R., Schmitt, C., De Aldama, R., and Mouret, J. B. (2015). A new method to evaluate simulation models: the calibration profile (CP) algorithm. Journal of Artificial Societies and Social Simulation, 18(1), 12.

Robic M.-C., (1982), Cent ans avant Christaller, une théorie des lieux centraux, L'Espace Géographique, 1, 5-12.

Robson B. (1973). Urban growth, an approach. London, Methuen.

Rozenblat, C. (2010). Opening the black box of agglomeration economies for measuring cities' competitiveness through international firm networks. Urban Studies, 47(13), 2841-2865.

Rozenblat, C. and Melançon, G. (Eds.) (2013). Methods for multilevel analysis and visualisation of geographical networks. Springer Netherlands.

Rozenblat C. Pumain D. Velasquez E. (Eds.) (2018). International and Transnational Perspectives on Urban Systems. Springer Nature, Advances in Geographical and Environmental Sciences.

Sanders, L., Pumain, D., Mathian, H., Guérin-Pace, F., and Bura, S. (1997). SIMPOP: a multiagent system for the study of urbanism. Environment and Planning B: Planning and design, 24(2), 287-305.

Schmitt C. (2014). Modélisation des systèmes de peuplement: de SimpopLocal à SimpopNet. Université Paris I, PhD dissertation.

Schmitt, C., Rey-Coyrehourcq, S., Reuillon, R., and Pumain, D. (2015), Half a billion simulations, evolutionary algorithms and distributed computing for calibrating the SimpopLocal geographical model. Environment and Planning B, 42(2), 300-315.

Swerts E. (2016) The rising stars of urban growth in China. http://geodivercity.parisgeo.cnrs.fr/blog/

Swerts, E., Denis, E., \& Mukhopadhyay, P. (2018). Diffuse Urbanization and Mega-Urban Regions in India: Between Reluctant and Restrictive Urbanism? in Rozenblat C. Pumain D. Velasquez E. (eds) International and Transnational Perspectives on Urban Systems, Springer, Singapore, 237-262.

Taaffe E., Morrill R., Gould P. (1963). Transport extension in underdeveloped countries, Geographical Review, 4, 503-529.

Tobler W. R. (1970). A Computer Movie Simulating Urban Growth in the Detroit Region. Economic Geography, Vol. 46, Supplement: Proceedings, International Geographical Union. Commission on Quantitative Methods (Jun., 1970), 234-240.

Tornqvist G.E. (1973). Systems of Cities and Information Flows, Lund Studies in Geography, Serie B, 38.

Vance J. E. (1970). The merchant's world: the geography of wholesaling. Prentice-Hall, Englewood Cliffs.

De Vries (1984). European Urbanization 1500-1800. London, Methuen.

Weidlich, W. (2006). Sociodynamics: A systematic approach to mathematical modelling in the social sciences. Courier Corporation.

Wilson, A. (1970). Catastrophe Theory and Bifurcation (Routledge Revivals): Applications to Urban and Regional Systems. Routledge (second ed. 2012).

Zipf G.K. (1941). National Unity and Disunity. Bloomington (Indiana), Principia Press. 